\title{
Construction of a high-performance air-breathing cathode using platinum catalyst supported by carbon black and carbon nanotubes
}

Zi'ang Xiong, Shijun Liao ${ }^{1}$, Sanying Hou, Haobin Zou, Dai Dang, Xinlong Tian, Haoxiong Nan, Ting Shu, Li Du

${ }^{1}$ Corresponding author. Tel./Fax: +86 208711 3586. E-mail address: chsjliao@ scut.edu.cn. 


\begin{abstract}
It is well recognized that pore structure and the hydrophilicity/ hydrophobicity balance are key factors for the cathodes of air-breathing proton exchange membrane fuel cells (AB-PEMFCs). In this work, we attempted to adjust the pore structure and hydrophilicity of an air-breathing cathode by using two types of catalysts, $\mathrm{Pt} / \mathrm{C}$ and Pt/CNT, to prepare the catalyst layer for the air-breathing cathode instead of using a single catalyst. An MEA with the dual-catalyst cathode exhibited significantly improved single-cell performance, which was affected by the ratio of $\mathrm{Pt} / \mathrm{C}$ to $\mathrm{Pt} / \mathrm{CNT}$. Our optimized MEA, which had a ratio of 54:46 in the cathode catalyst layer, achieved a current density of up to $290 \mathrm{~mA} \mathrm{~cm}^{-2}$ at $0.6 \mathrm{~V}$, which was $14 \%$ higher than that of a MEA without Pt/CNT. The Pt/CNT in the catalyst layer played the key role in the overall performance of the AB-PEMFC. We propose that the CNT improved charge transfer and enabled better electrical conductivity than carbon black. In addition, the tubular structure of Pt/CNT made the catalyst layer more porous and permeable to gas. Furthermore, the addition of Pt/CNT may have changed the cathode's hydrophilicity/hydrophobicity balance, giving the cathode better water balance and consequently yielding better performance.
\end{abstract}

Keywords: CNTs, low electrical resistance, proton transfer path, porosity, water management

\title{
1. Introduction
}

Air-breathing proton exchange membrane fuel cells (AB-PEMFCs) offer several advantages, including small volume, low operating temperature, high power density, high energy conversion efficiency, and zero emissions, making them ideal power sources for portable electronics or electric vehicles ${ }^{[1-2]}$. However, a key obstacle to 
making AB-PEMFC technology commercially available is cathode performance in an ambient atmosphere. The thickness and porosity of cathode catalyst layers (CLs) are important macroscopic parameters. The structure of a CL is influenced by both fabrication method and materials (e.g., the species and their ratio). Generally, the catalytic properties of the electrocatalysts are affected by the specific area, stacking density, electrical conductivity and electrochemical oxidation resistance of carbon supports, which are various with their shapes and structures ${ }^{[3]}$. Different carbon materials have been used as catalyst carriers, such as carbon black ${ }^{[4-5]}$, carbon nanotube $(\mathrm{CNT})^{[6-7]}$, carbon nanofiber ${ }^{[8-10]}$, Graphene sheet ${ }^{[11-13]}$ and so on. Vulcan XC72 carbon black has been most widely used to support metal nanoparticles because of its high surface area and low electrical resistance. However, both corrosion and the structural density of carbon black-based carriers cause the resulting electrocatalysts to suffer from low Pt utilization, poor durability, and low mass transport capability ${ }^{[14]}$.

The carbon nanotube (CNT) has a distinctive structure and unique properties, such as electrochemical oxidation resistance, good electrical conductivity, and high surface area ${ }^{[15]}$. Previous research has shown that CNT-supported Pt catalysts can increase the performance of PEMFCs ${ }^{[16-18]}$. The exchange current density on a metal/CNT electrode is much higher than on a metal/graphite or glassy carbon electrode $^{[19]}$.

Catalyst activity is highly dependent not only on particle size but also on the dispersion of $\mathrm{Pt}$ on the carriers. Generally, the electrical conductivity of carbon supports significantly affects the catalytic activity; the higher the carbon's graphitization degree, the better the electrical conductivity ${ }^{[20-21]}$. However, the 3D character of a CNT catalyst layer is not suitable for gas conditions, since only the Pt nanoparticles that are very close to the membrane (i.e., within $10 \mu \mathrm{m}$ ) are the active 
components at the anode (and the cathode) of $\mathrm{H}_{2} / \mathrm{O}_{2}$ fuel cells ${ }^{[22]}$.

In this work, we designed MEAs by mixing $\mathrm{Pt} / \mathrm{CNT}$ and $\mathrm{Pt} / \mathrm{C}$ together in the cathode CL, hoping to enhance the utilization and electrochemical performance of $\mathrm{Pt}$ nanoparticles, since CNTs can bridge adjacent carbon black particles and inhibit the aggregation of carbon spheres. Pt/C filled the spaces within the framework constructed by Pt/CNT. The electron transfer rate depended on the distance between electron donor and electron accepter, and the interaction within $\mathrm{Pt} / \mathrm{CNT}$ or between $\mathrm{Pt} / \mathrm{C}$ and $\mathrm{Pt} / \mathrm{CNT}$ enhanced the electrical conductivity. In addition, high porosity led to a high mass transport rate, caused by the CNTs overlapping with one another. The micromorphology of the cathode CLs was characterized by scanning electron microscopy (SEM). Contact angle and electrochemical impedance spectroscopy (EIS) were used to evaluate each CL's performance in a single AB-PEMFC.

\section{Experimental}

\subsection{Preparation of the Pt/CNT}

The Pt/CNT catalysts were prepared using an organic colloid method reported previously by our group ${ }^{[23]}$. The Pt content of the prepared catalysts was ca. $40 \mathrm{wt} \%$. The typical procedure included the following steps. First, sodium citrate was dissolved in ethylene glycol, then the mixture was ultrasonically dispersed for $30 \mathrm{~min}$ to entirely dissolve the citrate. Next, hexachloroplatinic acid was thoroughly mixed with the resulting solution. Then the CNTs were added into the mixture, which was then stirred, after which $\mathrm{KOH} /$ ethylene glycol solution was added drop-wise to make the $\mathrm{pH}$ less than 10 . Second, the mixture was transferred into an autoclave with a Teflon liner and left to react at $170^{\circ} \mathrm{C}$ for $480 \mathrm{~min}$; after this, the $\mathrm{pH}$ was adjusted to below four by adding $10 \% \mathrm{HNO}_{3}$. Last, the reactant was filtered and washed, then 
dried in a vacuum drying oven overnight at $60^{\circ} \mathrm{C}$. Ethylene glycol was used as the solvent as well as the reducing agent, sodium citrate was used as a complexing agent and stabilizer, and multiwalled CNTs were used as the carriers.

\subsection{Preparation of the MEAs}

Nafion 211 membranes (DuPont, USA) were treated at $80^{\circ} \mathrm{C}$ in a $5 \mathrm{wt} \% \mathrm{H}_{2} \mathrm{O}_{2}$ aqueous solution for $0.5 \mathrm{~h}$, then treated in $0.5 \mathrm{M} \mathrm{H}_{2} \mathrm{SO}_{4}$ solution at $80^{\circ} \mathrm{C}$ for $0.5 \mathrm{~h}$, and subsequently in distilled water at $80^{\circ} \mathrm{C}$ for another $0.5 \mathrm{~h}$. We then mixed a commercial Johnson Matthey Hispec $4100 \mathrm{Pt} / \mathrm{C}$ catalyst (40 wt\%) (denoted as JM $\mathrm{Pt} / \mathrm{C}$ ) with Nafion dispersion (5\% Nafion ionomer solution, DuPont, USA) and isopropanol (IPA) using sonication for $0.5 \mathrm{~h}$ to fabricate the anode CLs. The Pt loading at the anode was $0.2 \mathrm{mg} \mathrm{cm}^{-2}$, and the dry Nafion content in the anode CLs was adjusted to $25 \mathrm{wt} \%$. Cathode inks were prepared by mixing $\mathrm{JM} \mathrm{Pt} / \mathrm{C}$, homemade Pt/CNT, Nafion dispersion, Teflon (60 \% PTFE dispersion, Aldrich, USA), and IPA. The weight percentages of $\mathrm{Pt} / \mathrm{CNT}$ in terms of the total amount of $\mathrm{JM} \mathrm{Pt/C}$ and Pt/CNT were $0,31,46,62$, and 100, respectively. Teflon (60\% PTFE dispersion) was added to the catalyst ink to replace part of the Nafion and thereby make the cathode CLs hydrophobic. The PTFE content with respect to the entire cathode CL was 10 wt $\%$, the dry Nafion content in the anode CLs was adjusted to $15 \mathrm{wt} \%$, the Pt loading at the cathode was $0.3 \mathrm{mg} \mathrm{cm}^{-2}$, and the active electrode area was $26 \mathrm{~cm}^{2}$. The inks were sprayed on both sides of a Nafion 211 membrane to form the CLs. We have labeled MEAs with a Pt/CNT content in the cathode of 0, 31, 46, 62, and $100 \mathrm{wt} \%$ MEA-CNT0, MEA-CNT31, MEA-CNT46, MEA-CNT62, and MEA-CNT100, respectively.

\subsection{Physical Characterization of the MEAs}

We observed the thickness of the cathode CLs using a scanning electron 
microscope (S-3700N, Japan). The samples for cross-sectional SEM were fabricated by breaking up the MEAs in liquid nitrogen to acquire smooth cathode cross-sections. We also measured the static contact angle using a contact angle meter (OCA 40 Micro, DataPhysics, Germany) with a droplet volume of $5 \mu \mathrm{L}$. EIS measurements were carried out at a cell voltage of $0.8 \mathrm{~V}$ with an amplitude of $5 \mathrm{mV}$ and in the frequency range of $10 \mathrm{kHz}$ to $100 \mathrm{mHz}$. The pore size distribution in the CL was measured by cutting into pieces membranes that on one side were covered with cathode CLs and on the other side had nothing, then using a Tristar 3020 (Micromeritic, USA).

\subsection{Single-cell Evaluation of the MEAs}

The MEAs were tested with our designed air-breathing testing cell on an FCT Fuel Cell Testing System (Arbin, USA), in an air-conditioned room at a temperature of $26^{\circ} \mathrm{C}$. The cell temperature was not controlled because the cathode was open to the atmosphere. The flow rate of dry hydrogen was tuned according to the discharge current, and the cathode obtain oxygen directly by exposure to the atmosphere.

\section{Results and Discussion}

Generally, water management is one of the biggest challenges for PEMFCs ${ }^{[24]}$. Cathode flooding causes diminished performance in the high current density region. Fig. 1 shows the water management ability of cathode CLs containing different amounts of $\mathrm{Pt} / \mathrm{CNT}$. It can be seen that the addition of $\mathrm{Pt} / \mathrm{CNT}$ enhanced the hydrophobicity of the cathode CL. This is attributable to an enlargement of the cathode CL's accessible specific surface area; the reduced stacking density of the CL led to uniform distribution of Nafion and PTFE within the CL. Well-dispersed binders resulted in superior water management in MEA-CNT46 and consequently better performance. 
Figs. 2 and 3 present, respectively, surface and cross-sectional SEM micrographs of cathode CLs containing different amounts of Pt/CNT. The images show that the catalysts were uniformly dispersed and the $\mathrm{Pt} / \mathrm{C}$ was successfully inserted into the CNT skeleton (see Fig. 2). The composite catalysts exhibited porous and cross-linked architectures, different from those of carbon black and the CNTs. Cathode CLs containing Pt/CNT and Pt/C exhibited more macropores than the $\mathrm{CL}$ with only Pt/C, suggesting that the presence of Pt/CNT enlarged the spaces within the CL. The stacking density of $\mathrm{Pt} / \mathrm{C}$ was significantly reduced by mixing $\mathrm{Pt} / \mathrm{CNT}$ and $\mathrm{Pt} / \mathrm{C}$, consequently enhancing the mass transportation and electrochemical performance of the AB-PEMFC. The Pt/C filled the macropores between the CNTs, helping to reduce the charge-transfer reaction resistance, as we will discuss later. To explore the variation in CL stacking density, we used SEM to measure the thickness of cross-sections of the cathode CLs.

Fig. 3 shows cross-sections of the cathode CLs. We found that the thickness of the CLs increased with the amount of added Pt/CNT; the maximum and minimum thicknesses were 16.54 and $10.83 \mu \mathrm{m}$. Our previous study ${ }^{[25]}$ indicated that the thickness of a cathode CL with an optimized cathode gas diffusion layer has little influence on the physical contact resistance, but the charge transfer resistance increases as the thickness of the cathode CL increases.

To evaluate the structure of the cathode CLs, we characterized their pore size distribution using a nitrogen adsorption method. As shown in Fig. 4, the peak pore diameter of MEA-CNT0 was in the range of 40 to $100 \mathrm{~nm}$; in contrast, after the addition of $\mathrm{Pt} / \mathrm{CNT}$, the pore diameter ranged from 110 to $170 \mathrm{~nm}$. Our results indicated that the presence of $\mathrm{Pt} / \mathrm{CNT}$ and $\mathrm{Pt} / \mathrm{C}$ made the pore size larger and the pores more widely distributed. 
To understand how the Pt/CNT affected cell performance, we used I-V curves and electrochemical characterization to quantify the main sources of voltage loss. Fig. 5 present the performance of single cells containing different amounts of $\mathrm{Pt} / \mathrm{CNT}$ in the cathode CL. Compared to MEA-CNT0, MEA-CNT100 (with 100 wt\% Pt/CNT in the cathode CL) showed inferior performance in the kinetic and ohmic regions, while the other three MEAs with Pt/CNT in the cathode CL exhibited better performance across the whole current density region. This explicitly indicated that the coexistence of appropriate amounts of $\mathrm{Pt} / \mathrm{CNT}$ and $\mathrm{Pt} / \mathrm{C}$ in the cathode $\mathrm{CL}$ reduced the charge transfer and mass transfer resistance. MEA-CNT46 achieved the best performance: at a working voltage of $0.6 \mathrm{~V}$, the current density was $290 \mathrm{~mA} \mathrm{~cm}{ }^{-2}$, which was $14 \%$ higher than that of MEA-CNT0 $\left(250 \mathrm{~mA} \mathrm{~cm}{ }^{-2}\right)$. Evidently, having an appropriate amount of Pt/CNT in the cathode CL played the key role in the overall performance of the AB-PEMFC; too much Pt/CNT decreased the cell performance. We propose that the CNTs improved charge transfer and enhanced electrical conductivity more than carbon black ${ }^{[26]}$. In addition, the tubular structure of Pt/CNT made the CL more gas permeable.

To further explore the electrode process kinetics of our MEAs, EIS was used to quantify the voltage loss contributions from the different electrochemical processes. Fig. 6 presents the EIS curves of MEAs with different amounts of Pt/CNT in the cathode CL at a cell voltage of $0.8 \mathrm{~V}$. Through simulation with Ivium software, we determined the corresponding ohmic resistance $\left(\mathrm{R}_{\Omega}\right)$ and charge transfer resistance (Rct). The $\mathrm{R}_{\Omega}$ of the MEAs dropped as the amount of Pt/CNT in the cathode CL increased, up to $64 \mathrm{wt} \%$. This suggested that adding the appropriate amount of Pt/CNT to the cathode CL improved the MEA's performance, while too much had a negative impact. MEA-CNT46 showed the smallest charge transfer resistance, 
implying that it had a more efficient conductive layer than the other MEAs because the CNTs can be bridged across particles. The ohmic resistance of MEA-CNT62 was comparable to that of MEA-CNT46, but the former's charge transfer resistance was larger, which is attributable to the prolonged proton transfer path arising from superfluous Pt/CNT. The lower ohmic resistance of MEA-CNT100 compared with that of MEA-CNT0 may have stemmed from the $\pi$ electrons of the CNTs interacting with the Pt particles, and the Pt particles deposited on the outer shell of the CNTs interacting strongly with the carriers via $\pi$-bonding ${ }^{[27]}$.

\section{Conclusions}

Pt/CNT catalysts were successfully synthesized by a sol-gel method and added to cathode CLs to improve cell performance. SEM and pore size distribution results showed that the resulting MEAs had typical porous and cross-linked architectures, and that the synergistic effects between $\mathrm{Pt} / \mathrm{CNT}$ and $\mathrm{Pt} / \mathrm{C}$ enhanced the electrochemical activity of Pt particles. The fuel cell performance data indicated that adding an appropriate amount of Pt/CNT to the cathode CL significantly enhanced the ORR activity. MEA-CNT46, containing $46 \mathrm{wt} \% \mathrm{Pt} / \mathrm{CNT}$ in the cathode CL, exhibited the best performance: the current density at $0.6 \mathrm{~V}$ was $290 \mathrm{~mA} \mathrm{~cm}{ }^{-2}$, which was $14 \%$ higher than that of MEA-CNT0 $\left(250 \mathrm{~mA} \mathrm{~cm}^{-2}\right)$. We suggest that the better performance of the MEAs containing both $\mathrm{Pt} / \mathrm{CNT}$ and $\mathrm{Pt} / \mathrm{C}$ may have resulted from several factors: synergistic effects between $\mathrm{Pt} / \mathrm{CNT}$ and $\mathrm{Pt} / \mathrm{C}$, low electrical resistance, a short proton transfer path, porosity, and effective water management.

\section{Acknowledgments}

This work was supported by the National Science Foundation of China (NSFC 
Project Nos. 21276098, 21476088, 51302091, U1301245), the Ministry of Science and Technology of China (Project No. 2012AA053402), the Guangdong Natural Science Foundation (Project No. S2012020011061), and the Department of Education of Guangdong Province (Project No. 2013CXZDA003).

\section{References}

[1] Dyer CK. Fuel cells for portable applications. J Power Sources 2002;106(1):31-34.

[2] Dyer CK. Replacing the battery in portable electronics. Scientific American 1999;281:88-93.

[3] Antolini E. Carbon supports for low-temperature fuel cell catalysts. Applied Catalysis B: Environmental 2009;88(1):1-24.

[4] Xu F, Wang M-x, Sun L, Liu Q, Sun H-f, Stach EA, Xie J. Enhanced Pt/C catalyst stability using p-benzensulfonic acid functionalized carbon blacks as catalyst supports. Electrochim Acta 2013;94:172-81.

[5] Wang M-x, Xu F, Liu Q, Sun H-f, Cheng R-h, He H, Stach EA, Xie J. Enhancing the catalytic performance of $\mathrm{Pt} / \mathrm{C}$ catalysts using steam-etched carbon blacks as a catalyst support. Carbon $2011 ; 49(1): 256-65$.

[6] Zhang S, Shao Y, Yin G, Lin Y. Self-assembly of Pt nanoparticles on highly graphitized carbon nanotubes as an excellent oxygen-reduction catalyst. Applied Catalysis B: Environmental 2011;102(3-4):372-7.

[7] Esmaeilifar A, Yazdanpour M, Rowshanzamir S, Eikani MH. Hydrothermal synthesis of Pt/MWCNTs nanocomposite electrocatalysts for proton exchange membrane fuel cell systems. Int $\mathbf{J}$ Hydrogen Energy 2011;36(9):5500-11. 
[8] Chang Y, Han G, Li M, Gao F. Graphene-modified carbon fiber mats used to improve the activity and stability of Pt catalyst for methanol electrochemical oxidation. Carbon 2011;49(15):5158-65.

[9] Lee C-L, Chao Y-J, Chen C-H, Chiou H-P, Syu C-C. Graphite-nanofiber-supported porous Pt-Ag nanosponges: Synthesis and oxygen reduction electrocatalysis. Int $\mathrm{J}$ Hydrogen Energy 2011;36(23):15045-51.

[10] Lee K, Zhang J, Wang H, Wilkinson DP. Progress in the synthesis of carbon nanotube-and nanofiber-supported Pt electrocatalysts for PEM fuel cell catalysis. J Appl Electrochem 2006;36(5):507-22.

[11] Kou R, Shao Y, Wang D, Engelhard MH, Kwak JH, Wang J, Viswanathan VV, Wang C, Lin Y, Wang Y. Enhanced activity and stability of Pt catalysts on functionalized graphene sheets for electrocatalytic oxygen reduction. Electrochemistry Communications 2009;11(5):954-7.

[12] Yoo E, Okata T, Akita T, Kohyama M, Nakamura J, Honma I. Enhanced electrocatalytic activity of Pt subnanoclusters on graphene nanosheet surface. Nano letters 2009;9(6):2255-9.

[13] Si Y, Samulski ET. Exfoliated graphene separated by platinum nanoparticles. Chemistry of Materials 2008;20(21):6792-7.

[14] Saha M S, Chen Y, Li R, et al. Enhancement of PEMFC performance by using carbon nanotubes supported Pt Co alloy catalysts[J]. J Chemical Engineering, 2009, 4(1):12-16.

[15] Li YG, Zhou W, Wang HL, Xie LM, Liang YY, Wei F, Idrobo JC, Pennycook SJ, Dai HJ. An oxygen reduction electrocatalyst based on carbon nanotube-graphene complexes. Nature Nanotechnology 2012;7(6):394-400.

[16] Zhang W, Sherrell P, Minett AI, Razal JM, Chen J. Carbon nanotube architectures as catalyst supports for proton exchange membrane fuel cells. Energy \& Environmental Science 2010;3(9):1286. 
[17] Wang X, Waje M, Yan YS. CNT-based electrodes with high efficiency for PEMFCs. Electrochemical and Solid State Letters 2005;8(1):A42-A44.

[18] Britto PJ, Santhanam KSV, Rubio A, Alonso JA, Ajayan PM. Improved Charge Transfer at Carbon Nanotube Electrodes. Advanced Materials 1999;11(2):154-157.

[19] Yu X, Ye S. Recent advances in activity and durability enhancement of Pt/C catalytic cathode in PEMFC: part I. Physico-chemical and electronic interaction between Pt and carbon support, and activity enhancement of Pt/C catalyst. J Power Sources 2007;172(1):133-144.

[20] Mattia D, Rossi M, Kim B, Korneva G, Bau H, Gogotsi Y. Effect of graphitization on the wettability and electrical conductivity of CVD-carbon nanotubes and films. J Physical Chemistry B 2006;110(20):9850-9855.

[21] Serp P, Corrias M, Kalck P. Carbon nanotubes and nanofibers in catalysis. Applied Catalysis A: General 2003;253(2):337-358.

[22] Villers D, Sun S, Serventi A, Dodelet J, Desilets S. Characterization of Pt nanoparticles deposited onto carbon nanotubes grown on carbon paper and evaluation of this electrode for the reduction of oxygen. J Physical Chemistry B 2006;110(51):25916-25925.

[23] Liao S, Holmes KA, Tsaprailis H, Birss VI. High performance PtRuIr catalysts supported on carbon nanotubes for the anodic oxidation of methanol. $J$ American Chemical Society. 2006;128(11):3504-3505.

[24] Yousfi-Steiner N, Moçotéguy P, Candusso D, Hissel D, Hernandez A, Aslanides A. A review on PEM voltage degradation associated with water management: Impacts, influent factors and characterization. J Power Sources 2008;183(1):260-274.

[25] Xiong Z'a, Liao S, Dang D, Tian X, Hou S, Liu F, Peng H, Fu Z. Enhanced water management in 
the cathode of an air-breathing PEMFC using a dual catalyst layer and optimizing the gas diffusion and microporous layers. Int J Hydrogen Energy 2015;40(10):3961-3967.

[26] Leela Mohana Reddy A, Ramaprabhu S. Pt/SWNT-Pt/C nanocomposite electrocatalysts for proton-exchange membrane fuel cells. J Physical Chemistry C 2007;111(44):16138-16146.

[27] Shao Y, Yin G, Gao Y, Shi P. Durability Study of Durability Study of Pt/C and Pt/CNTs Catalysts under Simulated PEM Fuel Cell Conditions. J Electrochem Soc 2006;153(6):A1093. 

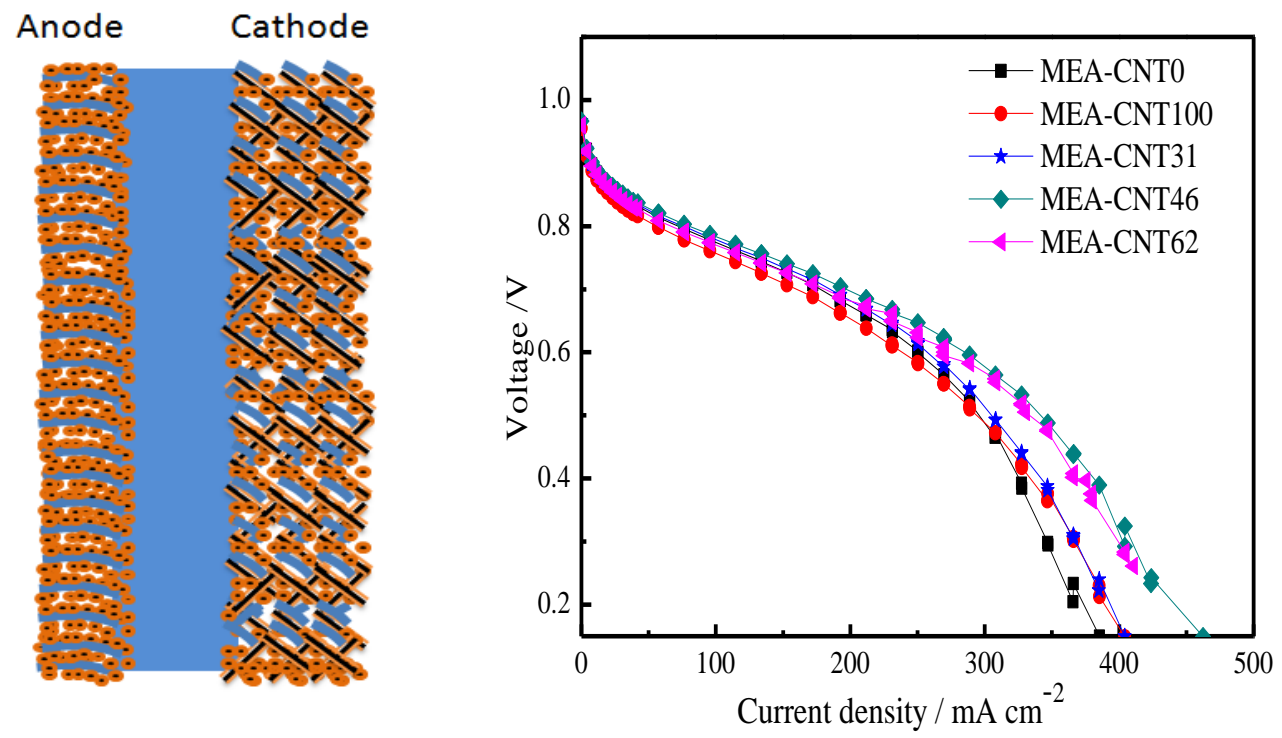

A high performance air-breathing cathode for air-breathing PEMFCs is prepared by using the mixture of $\mathrm{Pt} / \mathrm{C}$ and $\mathrm{Pt} / \mathrm{CNTs}$ as cathode catalysts. The significantly enhanced performance has been achieved by the PEMFC with the cathode. 

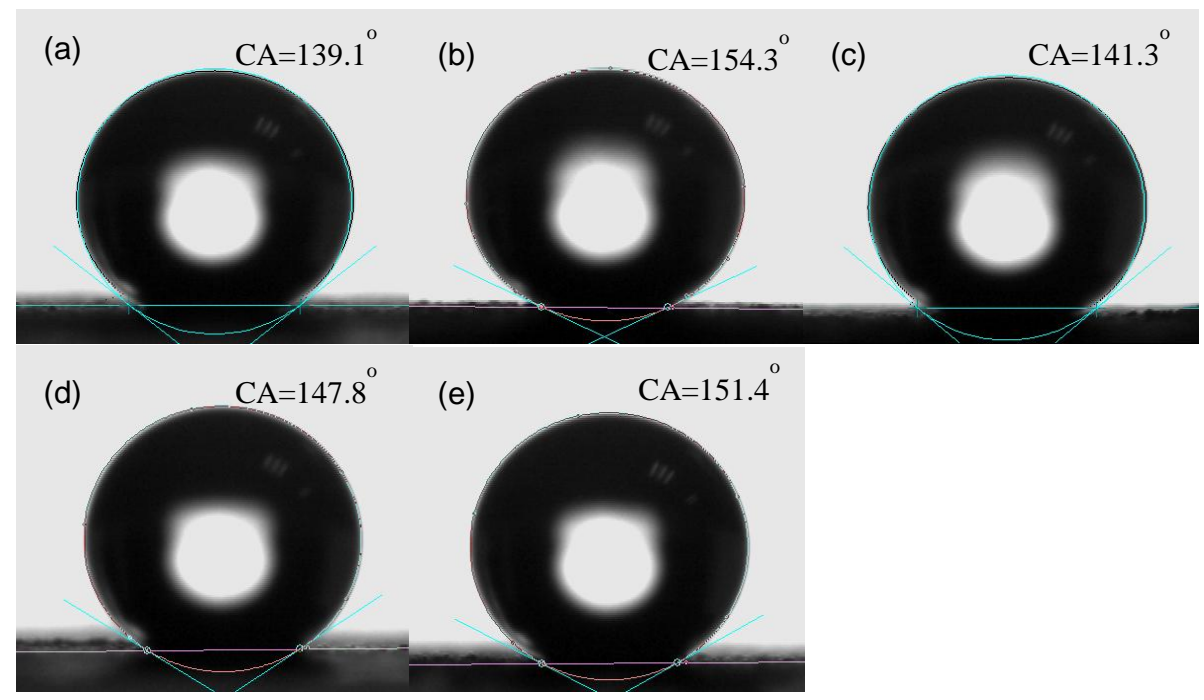

Fig. 1. Contact angle on the surface of the cathode CL of: (a) MEA-CNT0; (b) MEA-CNT100; (c) MEA-CNT31; (d) MEA-CNT46; (e) MEA-CNT62.

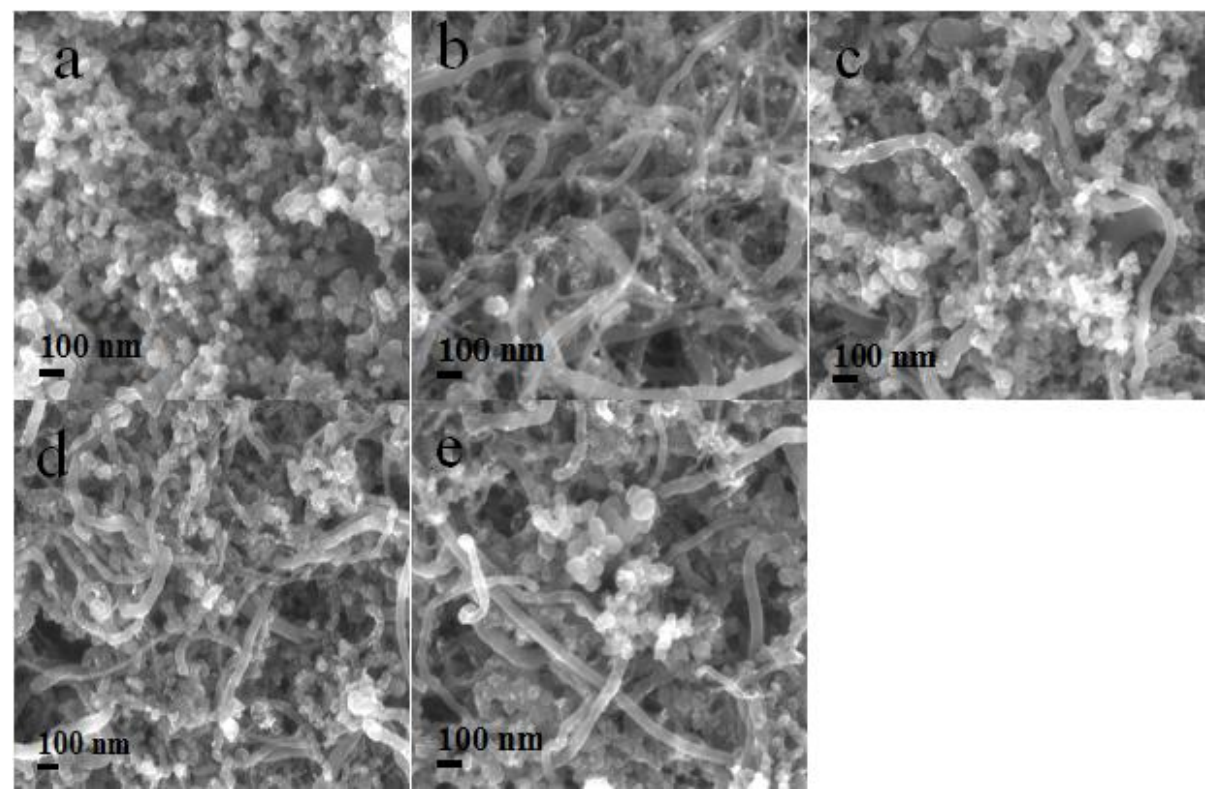

Fig. 2 SEM micrographs of cathode CLs: (a) MEA-CNT0; (b) MEA-CNT100; (c) MEA-CNT31; (d) MEA-CNT46; (e) MEA-CNT62. 


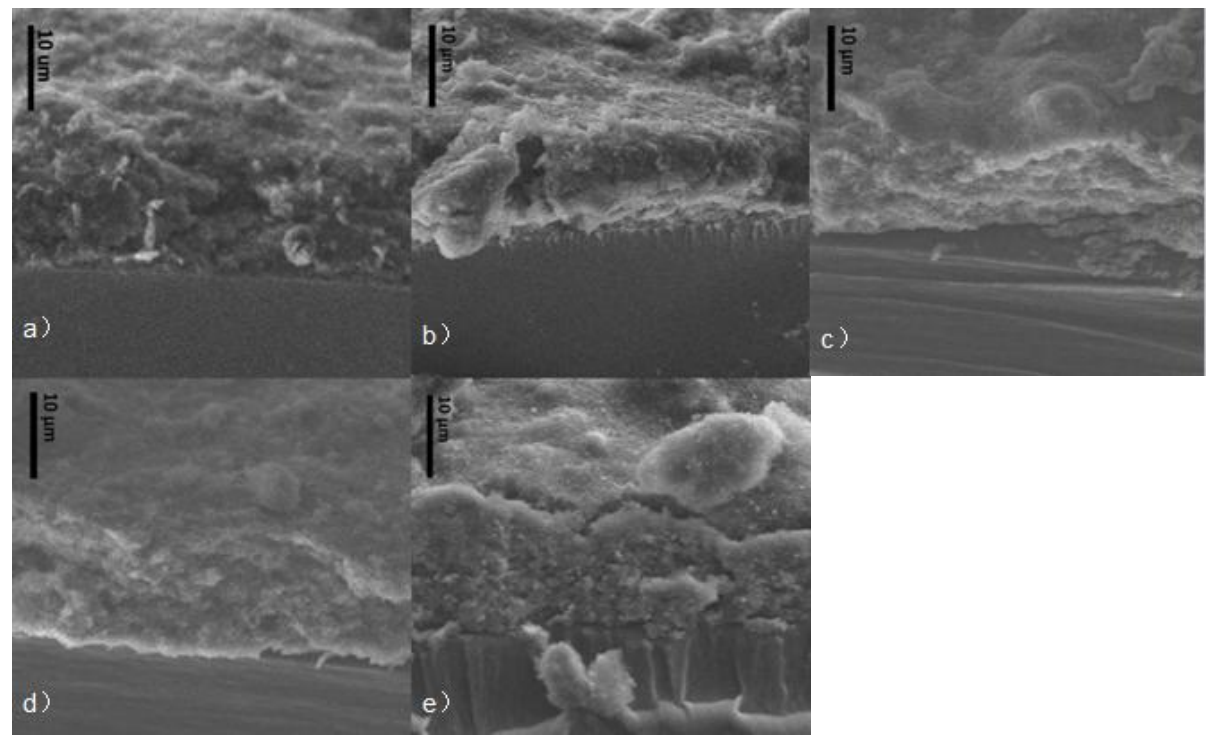

Fig. 3 SEM micrographs of cathode CL cross-sections: (a) MEA-CNT0; (b) MEA-CNT100; (c) MEA-CNT31;

(d) MEA-CNT46; (e) MEA-CNT62.

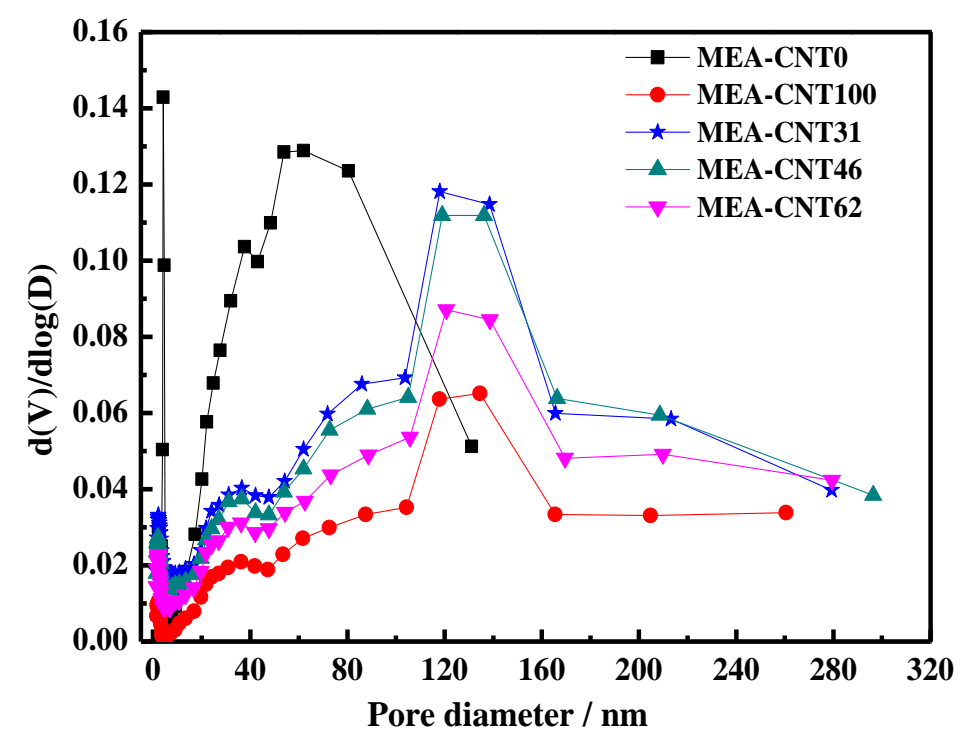

Fig. 4 Pore size distribution in various cathode CLs. 

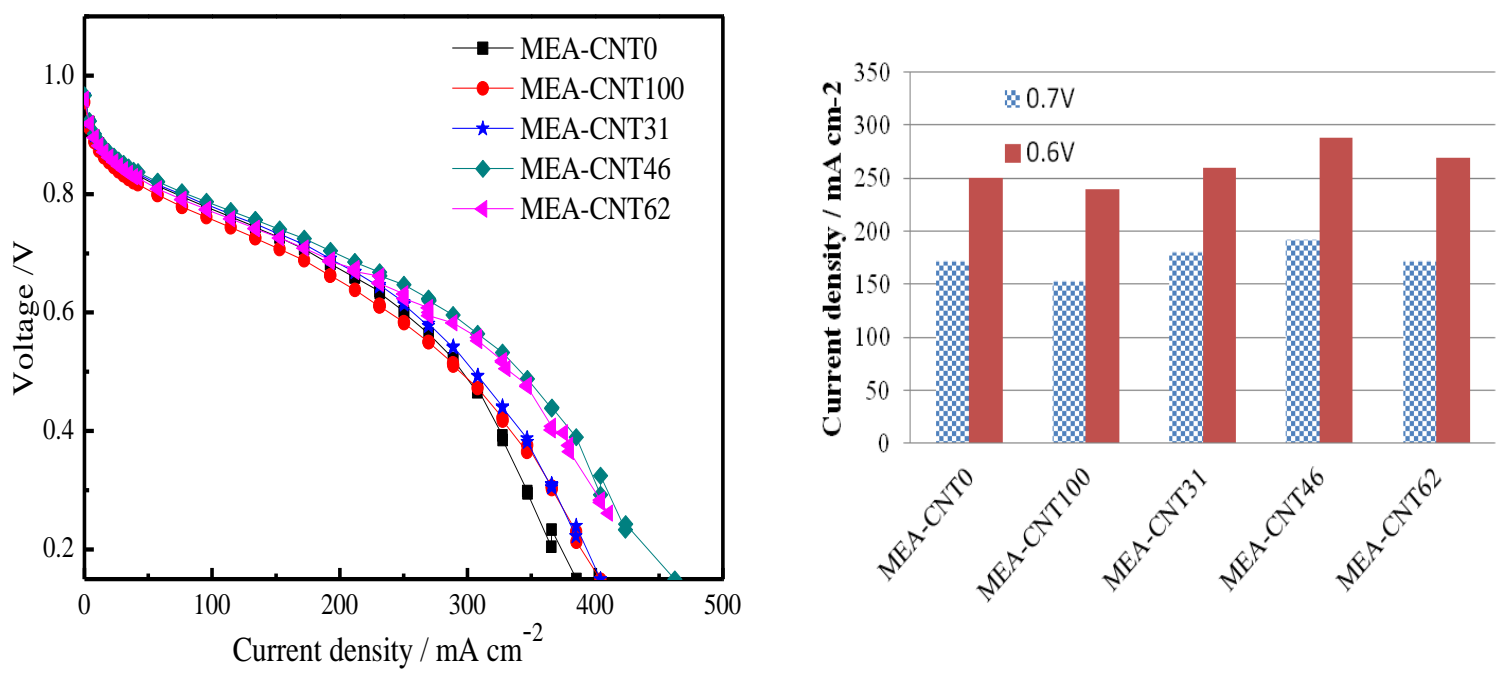

Fig. 5 Polarization curves obtained with different cathode catalyst compositions. Pt loading at the anode: 0.2 $\mathrm{mg}_{\mathrm{Pt}} \mathrm{cm}^{-2}$; Pt loading at the cathode: $0.3 \mathrm{mg}_{\mathrm{Pt}} \mathrm{cm}^{-2}$; room temperature.

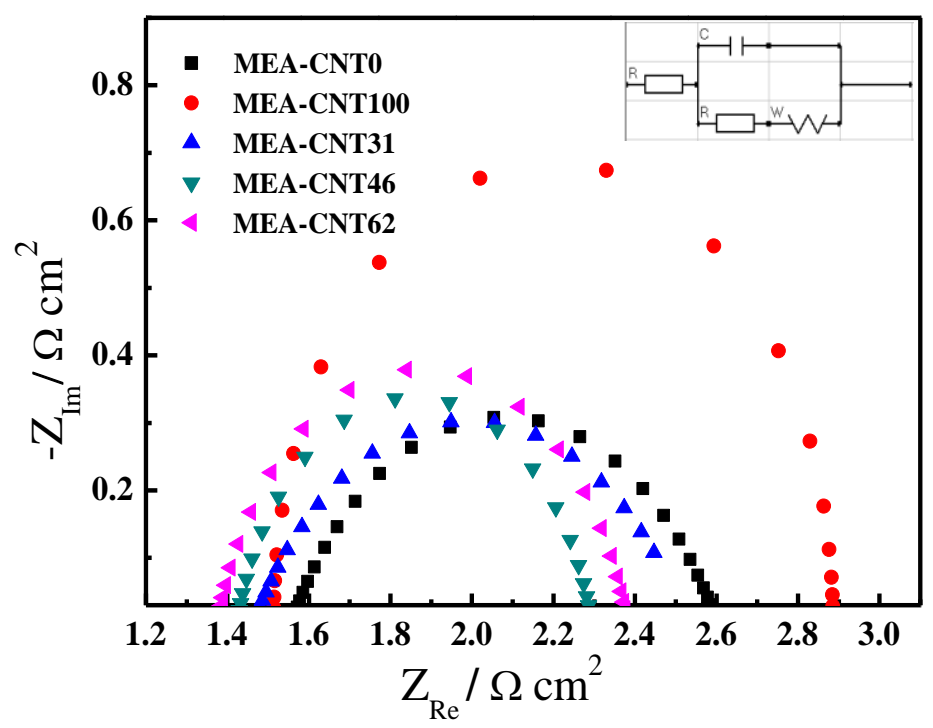

Fig. 6 EIS curves of MEAs with different cathode CL compositions. 